\title{
Pelatihan Pembuatan Peta Cabang Dan Ranting Muhammadiyah Menggunakan Aplikasi Sicara Untuk Mercepatan Pemetaan Cabang Dan Ranting Muhammadiyah Se-Kota Medan
}

\author{
Partaonan Harahap, Sudirman Lubis, Cholish \\ Program Studi Teknik Elektro, Fakultas Teknik \\ Universitas Muhammadiyah Sumatera Utara (UMSU) \\ J1. Kapten Muchtar Basri,BA No. 03 Medan Telp. (061) 6622400 ex. 12 Kode pos 20238 \\ e-mail: partaonanharahap@umsu.ac.id
}

\begin{abstract}
Abstrak - Berdasarkan amanat Muktamar tersebut LPCR telah melakukan serangkan program yang diantaranya adalah mengadakan pendataan secara nyata tentang kondisi Cabang dan Ranting Muhammadiyah di sejumlah wilayah di Indonesia. Tujuan dari pendataan tersebut adalah agar dapat memberikan gambaran nyata terhadap kondisi Cabang dan Ranting saat ini.Keberhasilan sebuah program akan mempengaruhi pelaksanaan program yang lain. Di masa-masa awal organisasi, tantangan yang dihadapi bersifat materi dimana sumber daya material sangat terbatas, namun di sisi lain ada semangat dan solidaritas yang berlimpah. Tantangan generasi awal muhammadiyah adalah bagaimana membangun basis materi sehingga organisasi dapat berjalan dengan stabil. Namun di tahap lanjut perkembangan sebuah organisasi situasi menjadi terbalik, di mana ketika basis materi sudah mapan biasanya tantangan yang muncul adalah bagaimana membangun dan mempertahankan solidaritas agar organisasi tetap berjalan dengan kompak. Pada output Aplikasi Sicara tersusun sebuah Peta dakwah yang terdiri dari yaitu Pimpinan Cabang Muhammadiyah, Pimpinan Ranting Muhammadiyah, Skoring keaktifan masingmasing PCM dan PRM, Letak Geografis untuk lokasi geografis PCM dan PRM, Musyawarah, Kepemilikan Kantor, Pengajian, Tempat Ibadah, Langganan suara Muhammadiyah.
\end{abstract}

\begin{abstract}
Kata kunci : Aplikasi Sicara, Peta Cabang dan Ranting Muhammadiyah
Abstract - Based on the mandate of the Conference, the LPCR has carried out a program which included conducting real data collection on the condition of Muhammadiyah Branches and Branches in a number of regions in Indonesia. The purpose of the data collection is to provide a real picture of the current condition of branches and branches. The success of a program will affect the implementation of other programs. In the early days of the organization, the challenges faced were material in which material resources were very limited, but on the other hand there was abundant enthusiasm and solidarity. The challenge of the early generation of Muhammadiyah was how to build a material base so that the organization could run stably. But in the later stages of the development of an organization the situation becomes reversed, where when the material base is established the challenges that usually arise are how to build and maintain solidarity so that the organization continues to run compactly. In the Speech Application output, a Da'wah Map consists of Muhammadiyah Branch Managers, Muhammadiyah Branch Leaders, active Scoring of PCM and PRM, Geographical Locations for PCM and PRM geographical locations, Deliberations, Office Ownership, Study, Study Places, Worship Activities, Voice Subscribers, Muhammadiyah.
\end{abstract}

Keywords : $\quad$ Speech Application, Map of Branches and Branches of Muhammadiyah

\section{PENDAHULUAN}

Sesuai amanat Muktamar ke-46, Cabang dan Ranting Muhammadyah harus terus tumbuh dan sehat dan aktif dalam menggerakkan dakwah dan pembangunan masyarakat sesuai dengan konteks kebutuhan lokal. Untuk mewujudkan amanat tersebut maka dibentuklah Lembaga Pemberdayaan cabang \& Ranting yang bertugas mendorong pertumbuhan Cabang dan Ranting Muhammadiyah sehingga mencapai $70 \%$ dari jumlah kecamatan dan $40 \%$ jumlah desa di seluruh Indonesia. Selain itu PCM dan PRM yang sudah ada juga didorong untuk meningkatkan kualitasnya sehingga benar-benar bisa menjadi ujung tombak dakwah persyarikatan dalam mewartakan semangat Islam berkemajuan, dan menjadi bagian dari problem solving tantangan yang dihadapi masyarakat. Demikianlah amanah Muktamar yang menjadi sasaran strategik LPCR sampai dengan tahun 2020

Berdasarkan amanat Muktamar tersebut LPCR telah melakukan serangkan program yang diantaranya adalah mengadakan pendataan secara nyata tentang kondisi Cabang dan Ranting Muhammadiyah di sejumlah wilayah di Indonesia. Tujuan dari pendataan tersebut adalah agar dapat memberikan gambaran 
nyata terhadap kondisi Cabang dan Ranting saat ini. Dalam proses pendataan, tim LPCR menemukan beragam potensi yang dimiliki oleh Cabang dan Ranting di seluruh pelosok Nusantara. Mulai dari Cabang dan Ranting yang memiliki amal usaha pendidikan dan kesehatan maju memiliki usaha ekonomi yang beragam, ketertiban administrasi organisasi, sampai dengan pembinaan jamaah dengan GJDJnya yang berhasil memajukan kualitas kehidupan sosial masyarakat. Tentu saja hal ini patut kita syukuri bersama.

Namun demikian tidak sedikit juga Cabang dan Ranting masih harus berjuang untuk dapat tumbuh dan memiliki kondisi yang sehat. Beragam faktor yang menyebabkan hal ini terjadi, tetapi pada umumnya adalah karena kurangnya semangat berjuang dan kapabilitas dalam mengelola Cabang dan Ranting sesuai dengan tantangannya masing-masing. Tentu saja kondisi ini harus diperhatikan secara serius dan perlu dicari upaya-upaya agar Cabang dan Ranting tersebut dapat mengatasi permasalahanya sehungga mampu tumbuh dan sehat, bermanfaat bagi umat dan masyarakat.

Diharapkan ketika Cabang dan Ranting tumbuh dan sehat maka dapat berperan aktif dalam menggerakkan dakwah dan pembangunan masyarakat sesuai dengan kebutuhan lokal. Salah satu aspek penting yang merupakan ciri bahwa Cabang dan Ranting Muhammadiyah tumbuh adalah adanya keunggulan program atau amal usaha yang diakui oleh pemerintah dan masyarakat, salah satunya adalah kemandirian dalam bidang ekonomi. Dengan ekonomi yang mandiri maka Cabang dan Ranting dapat membiayai sendiri program-programnya tanpa harus menggantungkan dari pihak lain Untuk itu LPCR PPM berinisiatif untuk mengadakan pertemuan bisnis Cabang dan Ranting dimana Cabang dan Ranting yang telah mandiri ekonominya dapat menularkan keberhasilannya kepada yang lain sehingga kesuksesan mereka bisa bergulir ke Cabang dan Ranting lainnya.

Berdasarkan paparan di atas maka peneliti perlu melakukan penelitian Pengaruh Aplikasi SICARA (Sistem Cabang Dan Ranting) Pada Program Dakwah Muhammadiyah Dan Dampaknya terhadap Pengembangan Cabang Dan Ranting Muhammadiyah. Maka perlu untuk menyelenggarakan Cabang dan Ranting yang dapat menjadi wahana saling bertukar pikiran dan pengalaman dalam mengembangkan Cabang dan Ranting Muhammadiyah.

Pada Kondisi Aktual Cabang Dan Ranting secara kuantitas, jumlah Cabang dan terutama Ranting Muhammadiyah masih terhitung minim. Dari 5.263 jumlah kecamatan di Indonesia, baru 3.221 yang memiliki Cabang Muhammadiyah atau sekitar 61\%. Sementara di tingkat Ranting kondisinya lebih parah, karena baru ada 8.107 Ranting Muhammadiyah dari 62.806 jumlah desa yang ada, atau hanya $12 \%$. Dari angka-angka di atas tampak bahwa pengaruh dan popularitas Muhammadiyah belum tercermin dalam kuantitas organisatorisnya. Secara kualitas, meskipun jika dibanding dengan beberapa ormas islam yang lain Muhammadiyah jauh lebih unggul, namun masih jauh dari harapan warga Muhammadiyah sendiri.

Pertama, secara organisatoris masih rapuh. Masih banyak Cabang dan Ranting yang belum memiliki kepengurusan yang lengkap, dan belum mampu menjalankan tertib organisasi, dalam hal adinistrasi, keuangan, maupun kegiatan.

Kedua, belum adanya tertib organisasi menyebabkan kepengurusan Cabang dan Ranting rentan konflik internal, terutama terkait dengan pengelolaan amal usaha.

Ketiga, lemah inisiatif, cenderung pasif dan menunggu instruksi dari atas.

Keempat, kondisi di atas diperparah oleh fakta bahwa SDM pimpinan Cabang dan Ranting masih banyak didominasi oleh kalangan usia lanjut.

Kelima, akibatnya Cabang dan Ranting Muhammadiyah cenderung monoton dalam mengadakan kegiatan, serta kurang mampu merespon perkembangan dan tuntutan lokalitas.

Keenam, kondisi di atas akhirnya membuat organisasi di tingkat Cabang dan Ranting memiliki daya saing yang rendah dibanding organisasi Islam baru yang banyak bermunculan, yang telah banyak "mengambil alih" jamaah maupun amal usaha Muhammadiyah.

Muhammadiyah adalah gerakan dakwah yang bercita-cita terwujudnya masyarakat Islam yang sebenar-benarnya, oleh karena itu untuk mewujudkan cita-cita tersebut Muhammadiyah perlu melakukan dakwah ke seluruh lapisan masyarakat, strata sosial, semua profesi dan kelompok kepentingan. Untuk memperlancar gerakan dakwah Muhammadiyah serta mempermudah koordinasi dan kesamaan visi maka dibangunlah struktur organisasi Muhammadiyah, mulai dari pusat untuk tingkat nasional, wilayah untuk tingkat propinsi, daerah untuk tingkat kabupaten/kota, Cabang untuk tingkat kecamatan atau untuk kumpulan beberapa Ranting, dan paling bawah adalah Ranting untuk tingkat desa atau kumpulan anggota. Struktur terendah yang merupakan tempat berkumpulnya anggota binaan dakwah Muhammadiyah adalah di tingkat Ranting. Dakwah Muhammadiyah akar rumput dibina oleh Ranting dan dikoordinasi oleh Cabang. Karena itulah posisi Ranting dan Cabang adalah sangat penting mengingat disinilah pembinaan langsung Muhammadiyah terhadap anggota-anggotanya.

Pada rumusan masalah ini, sesuai amanat Muktamar ke-46, Cabang dan Ranting Muhammadyah harus terus tumbuh dan sehat dan aktif dalam menggerakkan dakwah dan pembangunan masyarakat sesuai dengan konteks kebutuhan lokal. Untuk mewujudkan amanat tersebut maka 
dibentuklah Lembaga Pemberdayaan cabang \& Ranting yang bertugas mendorong pertumbuhan Cabang dan Ranting Muhammadiyah sehingga mencapai $70 \%$ dari jumlah kecamatan dan $40 \%$ jumlah desa di seluruh Indonesia. Diantaranya :

1. Kegiatan sosialisasi Percepatan pemetaan Cabang dan Ranting Muhammadiyah di 2 (dua) Zona yaitu Zona Satu di Kota Medan ( Aula Kantor PDM KOTA MEDAN ) dan Zona dua di PCM Sunggal (Aula Koprasi Surya Mandiri).

2. Pendataan Cabang dan ranting sesuai dengan quisioner

3. Penggunakan Aplikasi Sicara

Tujuan dari pendataan tersebut adalah agar dapat memberikan gambaran nyata terhadap kondisi Cabang dan Ranting saat ini. Dalam proses pendataan, tim LPCR menemukan beragam potensi yang dimiliki oleh Cabang dan Ranting di seluruh pelosok Nusantara. Mulai dari Cabang dan Ranting yang memiliki amal usaha pendidikan dan kesehatan maju memiliki usaha ekonomi yang beragam. Diantaranya Memekarkan PCM hingga $70 \%$ dari Jumlah kecamatan, Memberdayakan kepengurusan Cabang dan Ranting, Menghidupkan Kegiatan di Tingkat Cabang dan Ranting

\section{TINJAUAN PUSTAKA}

Selama lima tahun periode pertama keberadaan LPCR PDM Kota Medan, pemetaan merupakan program pertama dan utama, yang dilaksanakan dengan berbagai pendekatan bekerjasama dengan berbagai unit kelembagaan yang ada di lingkungan persyarikatan. Ada pendataan yang dilakukan sendiri oleh LPCR, ada yang dikerjakan langsung oleh struktur persyarikatan kerjasama antara PRM, PCM dan PDM. Kondisi ini terjadi, karena data masih belum dianggap urgent oleh kalangan pimpinan persyarikatan, sehingga program pendataan cenderung kurang mendapatkan perhatian serius.

Pada periode kedua yaitu 2015-2020, LPCR memiliki tugas dan karakter khusus: Pertama, bersifat lintas sektor karena mengkoordinasikan kegiatan dari berbagai dimensi dan perspektif, yang berlangsung di ranah akar rumput. Mulai dari tabligh, organisasi, pengembangan SDM, pemberdayaan ekonomi, pembinaan angkatan muda. Kedua, LPCR memiliki tugas pertama yang dijalankan oleh LPCR, di antaranya membenahi basis data terkait dengan jumlah cabang dan ranting serta peta kondisi yang ada dari cabang dan ranting.

Poin pertama merupakan batu pijakan yang terasa sangat berat, namun memiliki manfaat sangat besar. Tanggal 17 Desember 2016 dilaksanakan Rakerwil LPCR Muhammadiyah se-Sumatera Utara di Pandan, Kabupaten Tapanuli Tengah, waktu itu belum ada data basis yang resmi dan akurat terkait jumlah cabang dan ranting, baik di level PWM, PDM maupun PCM.

Ketiga, keberadaan peta kondisi cabang ranting, teridentifikasinya sejumlah PRM dan PCM unggul yang ada di Kota Medan. Yang menarik lagi, semakin terbukanya fakta bahwa keunggulan cabang dan ranting sangat beragam, mulai dari keunggulan jumlah jamaah, intensitas kegiatan, kuantitas dan kualitas amal usaha, hingga kreativitas program. Fakta ini semakin menyadarkan kepada kita bahwa pengembangan cabang dan ranting tidak dapat dilaksanakan dalam satu arah, melainkan harus multiperspektif sesuai dengan konteks potensi dan tantangan yang ada.

Keberadaan peta cabang dan ranting unggulan ini, memberikan inspirasi kepada LPCR untuk melakukan pemberdayaan secara sistematis dengan menggunakan metode "peer learning", di mana cabang dan ranting didorong untuk belajar kepada cabang dan ranting unggulan sesuai konteks potensi yang dimiliki.

Memasuki abad kedua, Muhammadiyah dihadapkan pada tugas dan tantangan baru yang makin berat, bukan hanya karena makin kompleksnya perkembangan masyarakat yang menuntut berbagai penyesuaian, namun juga kemunculan banyak organisasi Islam baru yang mengharuskan Muhammadiyah memperbarui strategi dakwah dan perjuangannya. Salah satu tantangan tersebut adalah penataan dakwah dan perjuangan di tingkat akar rumput melalui pengembangan Cabang dan Ranting.

Secara hirarkhi keorganisasian, Cabang dan Ranting adalah level organisasi paling bawah, sehingga sering juga dilihat dari logika garis wewenang dimana pimpinan Cabang dan Ranting sekedar pihak yang menunggu dan menjalankan perintah pimpinan yang di atasnya. Pimpinan Ranting Muhammadiyah (PRM) merupakan garda depan (ujung tombak) bagi Persyarikatan, yang menjadi barometer keberhasilan atau kegagalan Muhammadiyah baik sebagai gerakan sosial, organisasi, maupun missi dakwah Islam amar ma'ruf nahi munkar.

Sayangnya, selama ini PRM sekaligus menjadi segmen Persyarikatan yang paling menerima beban (ujung tombok), baik secara sosial, finansial, maupun politis. Ada anggapan bahwa Muhammadiyah tak lebih dari sebuah Yayasan besar, yang memiliki banyak lembaga pendidikan, kesehatan dan sosial. Anggapan tersebut mungkin berangkat dari asumsi bahwa Muhammadiyah banyak bersentuhan dengan masyarakat di tingkat bawah. Sebagian Pimpinan Muhammadiyah, mungkin mengorganisir ranting tidak penting. Ranting tidak menjanjikan popularitas dan materi.

Penguataan kapasitas organisasi, terutama pada struktur yang paling bawah, Pimpinan Ranting Muhammadiyah (PRM) sangat urgen untuk 
dilakukan, karena ranting memiliki peran yang sangat strategis sebagai duta peryarikatan di lingkungan sosial masyarakat desa dan kelurahan di Indonesia. Sebagai struktur pimpinan Muhammadiyah yang terhubung langsung dengan dinamika kehidupan masyarakat, PRM dituntut untuk ikut berkontribusi besar dalam menyelesaikan berbagai persoalan yang dihadapi masyarakat terutama persoalan tingginya angka kemiskinan baik di perdesaan maupun di kelurahan-perkotaan.

Ranting tidak menjanjikan popularitas dan materi. Ranting tak bersentuhan dengan pejabat, dan jauh dari media massa. Ranting-lah ujung tombak gerakan. Segala kebutuhan masyarakat, mulai dari kebutuhan pembinaan keagamaan, sampai persoalan sosial dan ekonomi, mesti ditanggapi secara cepat dan tepat oleh ranting. Sebagai gerakan dakwah, Muhammadiyah hingga kini telah menunjukkan kiprah yang membanggakan. Tetapi, harus diakui bahwa dalam tingkat tertentu kiprah dakwah Muhammadiyah belum mampu menjangkau ke semua lapisan masyarakat. Kesimpulan itu didasarkan kepada fakta bahwa dakwah Muhammadiyah terasa mudah diterima masyarakat perkotaan, tetapi sulit menembus basis massa di pedesaan

Pimpinan Muhammadiyah memiliki komitmen terhadap ranting, seharusnya salah satu syarat menjadi Pimpinan Persyarikatan, termasuk di level PPM dan PWM, adalah keaktifan sebagai pegiat ranting. Selain jalur-jalur struktural yang dimilikinya, Muhammadiyah juga mempunyai kelompokkelompok yang tersebar di tengah masyarakat dalam bentuk Jama'ah Muhammadiyah. Jama'ah Muhammadiyah merupakan lini di luar jalur-jalur struktural Muhammadiyah secara nyata melaksanakan dakwah Islamiyah yang sesuai dengan visi dan misi Muhammadiyah di tengah masyarakat.

Biasanya, Jama'ah Muhammadiyah bergerak dalam skala mikro di tengah masyarakat melalui masjid-masjid sebagai basis aktivitas. Aktivitas dakwah yang dilaksanakan dalam Jama'ah Muhammadiyah pun bermacam-macam, seperti pengajian, bakti sosial, infaq, zakat, shadaqah, dan lain-lain. Jama'ah Muhammadiyah tersebar di tengahtengah masyarakat melaksanakan aktivitas riil yang responsif bagi persoalan yang ditumbuh di kalangan masyarakat.

Meski demikian, ada beberapa catatan kritis terkait pemaknaan ranting. Dalam konteks masyarakat agraris, dimana orang lebih banyak menghabiskan waktu di sekitar tempat tinggalnya, makna ranting dalam cakupan geografis tidak menjadi persoalan. Namun dalam masyarakat industrial, masyarakat lebih banyak menghabiskan waktu di tempat kerja, bahkan menghabiskan waktu luang pun lebih sering dilakukan bersama teman seprofesi, atau dalam komunitas berbasis hobi. Dalam konteks seperti itu, mungkin ranting perlu diorganisir dalam komunitas berbasis profesi atau hobi.

Belum lagi, dalam masyarakat post-industrial, dimana masyarakat lebih sering berjumpa dalam ruang-ruang virtual. Perjumpaan melalui media sosial seperti facebook, twitter, whats-app, atau blackberry messenger, jauh lebih intensif dibanding pertemuan fisik. Kehadiran grup-grup di media sosial, mungkin dapat dimaknai sebagai wajah lain ranting, sepanjang grup itu dikelola dengan kesadaran untuk berbagi spirit pencerahan Muhammadiyah.

\section{Agenda Dan Tantangan Ke Depan}

Sejauh ini, dapat dikatakan program LPCR PDM Kota Medan termasuk paling progresif, baik di level PWM dan PDM se-Sumatera Utara. Di level PDM Kota Medan, LPCR selalu aktif dalam melakukan kegiatan-kegiatan terutama yang bersifat sinergi baik lintas Majelis/Lembaga maupun dengan jaringan AUM.

Bahkan kadangkala, LPCR dianggap terlalu agresif karena ikut mengurusi program kerja yang dianggap wewenang majelis atau lembaga lain. Namun, pimpinan LPCR Kota Medan menganggap bahwa apapun yang terkait dengan upaya pengembangan cabang dan ranting jika tidak ada yang melakukan, maka LPCR yang bertanggungjawab. Demikian juga di level PDM dan PCM, LPCR sering tampil sebagai lembaga yang progresif dan produktif. Hal ini tentu tidak lepas dari sistem koordinasi yang dikembangkan dan didukung oleh semangat para pimpinan LPCR .

Namun demikian meskipun capaian sudah sangat bagus LPCR masih memiliki agenda yang cukup berat. Pertama, dalam upaya meningkatkan kuantitas cabang dan ranting yang terlihat masih jauh dari target. Dalam hal ini ada catatan sosiologis. Pertama, Muhammadiyah adalah gerakan pembaharuan sehingga akan sulit menjadi kelompok mayoritas. Karena itu target pengembangan kuantitas perlu didasarkan pada kesadaran kualitas yaitu lebih kepada meningkatkan jangkauan pengaruh. Jumlah boleh minoritas, namun pengaruh mayoritas. Ini sudah dibuktikan bisa dilakukan di berbagai tempat.

Kedua, dalam kaitan dengan upaya peningkatan kuantitas dan juga peningkatan kualitas perlu tetap ditingkatkan pengembangan dan up-date pendataan kondisi cabang dan ranting. Peta yang sekarang ada sudah sangat membantu pimpinan persyarikatan untuk mengambil kebijakan dan merumuskan program yang lebih sesuai dengan kebutuhan. Kedepan akan sangat ideal apabila data yang ada dalam peta LPCR dapat disinkronkan dengan data yang dimiliki majelis dan lembaga yang ada di lingkungan persyarikatan, sehingga formulasi program maupun implementasi dapat dilakukan secara lebih sinergis. 
Selama ini LPCR sudah menjalin sinergi yang cukup baik dengan sejumlah majelis dan lembaga yang memiliki kedekatan program, seperti LAZISMU, Tabligh, MPM, Majelis Pustaka dan Informasi. Namun, sinergi yang selama ini dilakukan lebih bersifat spontan, berdasarkan kebutuhan di lapangan. Idealnya sinergi dilakukan mulai dari sinkronisasi basis data sehingga program yang disusun benar-benar berdasarkan kebutuhan kontekstual di lapangan dan potensi yang dimiliki oleh masing-masing majelis lembaga.

Misalnya, jika LPCR memiliki atau dapat mengakses basis data mubaligh di suatu cabang dan ranting, maka akan lebih memudahkan jika ada program pemberdayaan ataupun pemekaran cabang/ranting. Demikian juga ketika Majelis Pemberdayaan Masyarakat atau Lembaga Penanggulangan Bencana dibekali dengan peta kondisi Cabang dan Ranting akan memudahkan mereka di dalam mobilisasi potensi Persyarikatan dalam menyusun maupun implementasi program.

Ketiga, pemberdayaan ekonomi. Hal ini sangat penting sekaligus tidak bisa dipisahkan. Di satu sisi pengembangan ekonomi merupakan bagian yang terbukti tidak lepas dari keunggulan cabang dan ranting, dan pengembangan ekonomi. Keempat, mengaktifkan cabang dan ranting sebagai mekanisme peer learning dalam upaya percepatan pemberdayaan cabang dan ranting sesuai konteks dan potensi yang dimiliki. Sesuai dengan kesepakatan Rakornas LPCR Tahun 2018 di Kota Magelang Gunung Pring, setiap PDM diharapkan menunjuk minimal satu PCM dan tiga PRM unggulan.

Peta ini diharapkan akan dapat memfasilitasi keinginan PRM dan PCM di daerah setempat untuk dapat segera mungkin meningkatkan kualitas diri dengan cara yang sederhana yaitu meniru kepada Cabang/Ranting yang lebih baik yang ada di sekitarnya. Mungkin saja cabang dan ranting unggulan lokal belum sepenuhnya ideal sesuai dengan standar cabang ranting unggulan yang ditetapkan pada level nasional.

Namun demikian keberadaan unit unggulan lokal tetap akan sangat membantu sebagai langkah awal. Lebih jauh lagi untuk cabang dan rantung unggulan yang memang sudah memenuhi standar akan didorong untuk memiliki binaan yang secara khusus dibimbing secara sistematis. Nantinya tidak menutup kemungkinan salah satu kriteria tambahan dari keunggulan sebuah cabang dan ranting adalah keberadaan binaan yang dimiliki.

\section{Penggunaan SICARA}

Untuk mengakses halaman ini pertama kali kita harus menuliskan https://sicara.id di browser yang kita gunakan. Pada halaman ini kita hanya akan menemukan sebuah halaman dengan menu login di kanan atas. Klik menu login untuk mendapatkan halaman dengan formulir untuk login, Pada halaman ini diminta untuk memasukkan alamat email dan password. Alamaemail adalah akun yang sudah didaftarkan ke admin sicara yaitu LPCR PP Muhammadiyah.

Pasangan alamat email dan password yang sesuai dipastikan dapat digunakan untuk mengelola sicara pada masing-masing jenjang. Setelah kita masukkan email dan password maka kita lanjutkan dengan klik pada tombol "Login" pada form tersebut dan pengguna akan diarahkan pada halaman awal dari aplikasi sicara. Halaman Dashboardm aplikasi sicara. Pada dashboard ini nama pengguna akan muncul pada kanan atas dan nama organisasi yang dikelola akan muncul pada halaman dashboard juga. Menumenu yang tampil dan dapat digunakan pada aplikasi ini adalah sebagai berikut:

(1) input PCM

(2) Input PRM

(3) Laporan $\rightarrow$ Rekap

(4) Setting

(5) Change password

\section{METODE}

Lokasi dan Waktu Penelitian

Penelitian ini akan dilaksanakan Sosialisasi Penguatan dan Pemetaan Cabang Dan Ranting SeKota Medan, yang dibagi atas 2 Zona dan Bulan Februari 2019, Adapun pelasanaan di Zona 1 yaitu :

1. Pada taggal 10 Februari 2019,

Lokasi Aula PDM KOTA MEDAN

Jl. Mandala By Pass No. 140 Medan.

Kepesertaan Rayon 1 terdiri 17 PCM dan 73 Ranting. Peserta Utusan PCM sebanyak 3 orang/cabang, Peserta Utusan PRM sebanyak 2 orang/ranting.

2. Zona 2 Pada tanggal, 17 Februari 2019

Lokasi Aula Koprasi Surya Abadi Mandiri

Jl. Sei Mencirim No. 25 Medan Krio Sunggal

Deliserdang

Pada kondisi geografis, sosial dan budaya masyarakat diantaranya:

1. Secara rinci mengenai persiapan, pelaksanaan dan evaluasi meliputi :

a. Melanjutakan Pendataan dan Pemetaan Cabang dan Ranting melalui program Aplikasi SICARA

b. Pengembangan Cabang dan Ranting Unggulan dan Sekolah Cabang \& Ranting

c. Pengembangan GJDJ dan manajemen masjid dan mushola

d. Mobilisasi SDM (AMM) dan DANA untuk penguatan Cabang dan Ranting 
2. Metode yang dilakukan penelitian ini adalah :

Pada output Aplikasi Sicara tersusun sebuah Peta dakwah yang terdiri dari yaitu :

1. Perbandingan : untuk melihat perbanding jumlah kecamatan, desa dan PCM serta PRM

2. PCM : list skor PCM dan indikator warna

3. PRM : list Skor PRM dan Indikator warna

4. Skoring : grafik utk skor dan keaktifan masing-masing PCM dan PRM

5. Letak Geografis : grafik untuk lokasi geografis PCM dan PRM

6. Musyawarah : grafik untuk rekap tahun terakhir dari Muyscab dan Musyran

7. Kantor : grafik untuk status kepemilikan kantor sekretariat PCM dan PRM

8. Pengajian : grafik untuk menampilkan Pengajian di PCM dan PRM

9. Mubaligh : grafik untuk menampilkan Jumlah Mubaligh, Korps Mubaligh dan Kursus Mubaligh di PCM dan PRM

10. Tempat Ibadah : menu ini adalah berisi grafik kepemilikan masjid mushala di PCM dan PRM

11. Langganan SM : grafik untuk melihat jumlah berlangganan SM di PCM dan PRM

3. Rencana yang dilakukan untuk pengembangan unit PKPM pada tahun selanjutnya adalah :

1. Menjadi wahana bertukan pikiran dan pengalaman dalam mengembangkan dan memberdayakan Cabang dan Ranting Muhammadiyah

2. Menampilkan program unggulan Cabang dan Ranting Muhammadiyah terpilih sehingga dapat menjadi pembelajaran dan inspirasi Cabang dan Ranting lainnya.

\section{HASIL DAN PEMBAHASAN}

Sejauh ini, LPCR sudah melakukan banyak hal dan termasuk lembaga yang sangat progresif dan produktif di dalam menghasilkan program dan kegiatan. Namun demikian tentu saja masih banyak lagi tantangan yang harus dihadapi kedepan. berbagai program yang sudah dilaksanakan dan akan dilaksanakan sebenarnya merupakan suatu kesatuan yang saling mengikat. Berikut adalah Kegitan yang terealisasi

1. Sosialisasi Percepatan, Pemetaan Cabang dan Rantig Muhammadiyah , 10 Februari 2019 Aula PDM Kota Medan Khusus Zona 1

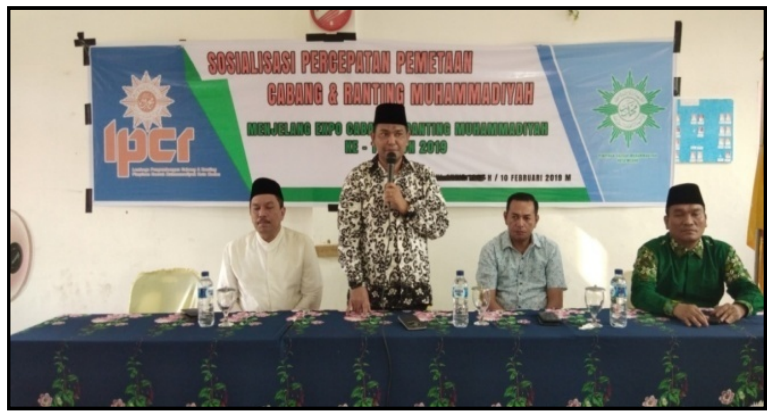

Gambar 1. Sosialisasi Percepatan, Pemetaan Cabang dan Rantig Muhammadiyah, 10 februari 2019 Aula PDM Kota Medan Khusus Zona 1

2. Sosialisasi Percepatan, Pemetaan Cabang dan Rantig Muhammadiyah , 17 Februari 2019 Aula Koprasi Surya Mandiri PCM Sunggal Jl. Sei Menciri Khusus Zona 2

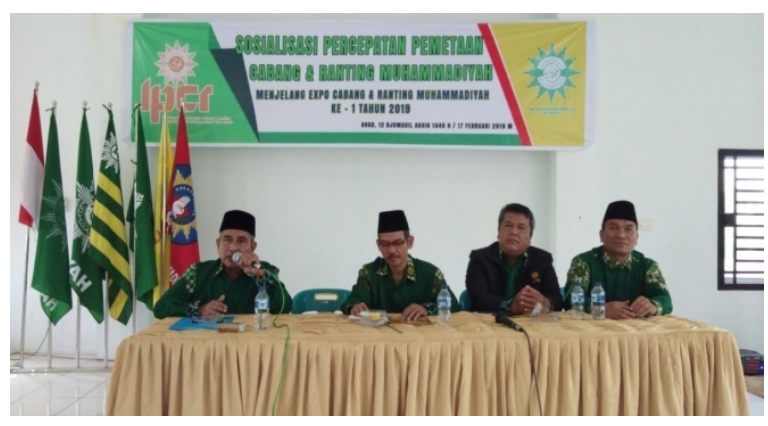

Gambar 2. Sosialisasi Percepatan, Pemetaan Cabang dan Rantig Muhammadiyah, 17 Februari 2019 Aula Koprasi Surya Mandiri PCM Sunggal Jl. Sei Menciri Khusus Zona 2

3. Kunjungan Eladang Edukasi, 17 Februari 2019 PCM Sunggal Jl. Sei Menciri

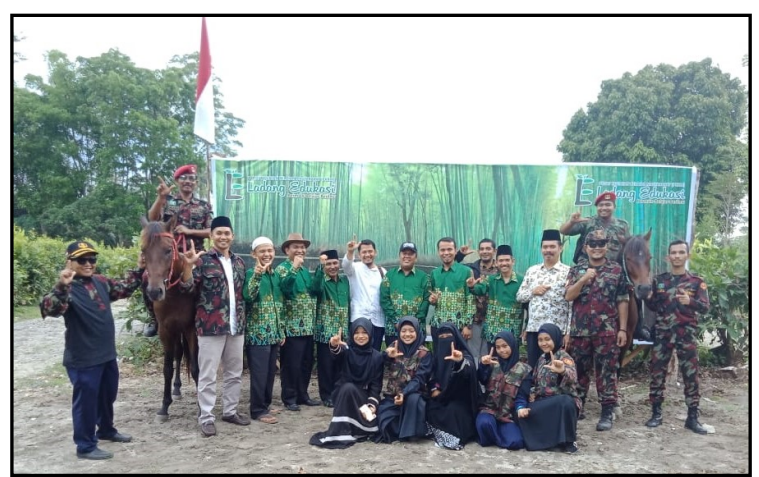

Gamabr 3. Eladang Edukasi , 17 Februari 2019 PCM Sunggal Jl. Sei Menciri 


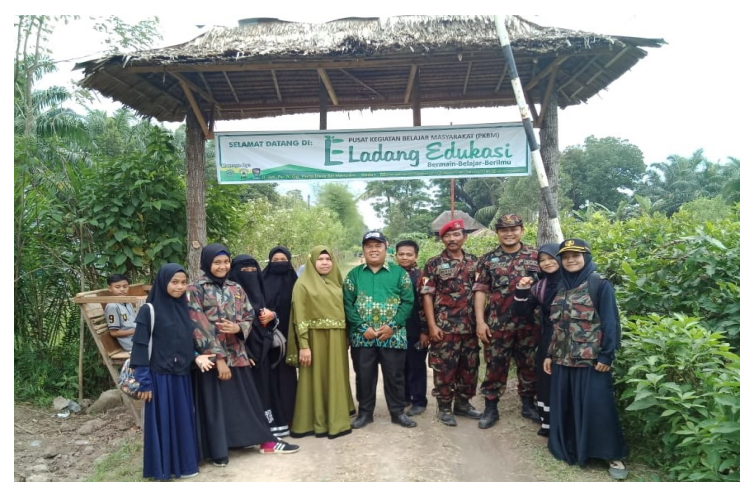

Gamabr 4. Eladang Edukasi, 17 Februari 2019 PCM Sunggal Jl. Sei Menciri

4. Halaman Dashboard

pada aplikasi sicara Pada dashboard ini nama pengguna akan muncul pada kanan atas dan nama organisasi yang dikelola akan muncul pada halaman dashboard juga. Menu-menu yang tampil dan dapat digunakan pada aplikasi ini adalah sebagai berikut:
(1) input PCM
(2) Input PRM
(3) Laporan $\rightarrow$ Rekap
(4) Setting
(5) Change password

Saat ini beberapa menu belum sepenuhnya berfungsi dan akan terus ditingkatkan utilitasnya pada tahap selanjutnya. Menu-menu tersebut akan dijelaskan pada tahapan panduan berikutnya. Dashboard juga menampilkan beberapa hasil entry yaitu Perbandingan Jumlah PCM dengan Kecamatan secara nasional (7), Perbandingan Jumlah Ranting dengan desa secara nasional (8), Persentase data PCM yang diinput (9), Persentase data PRM yang diinput (10), Progress Pencapaian Jumlah PCM dan Input data PCM per wilayah (11), Progress Pencapaian Jumlah PRM dan Input data PRM per wilayah (12), Rekap Jumlah Keaktifan PCM dan PRM secara nasional (13), serta data realtime input PCM/PRM (14). Tampilan Halaman Dashboard pada aplikasi sicara

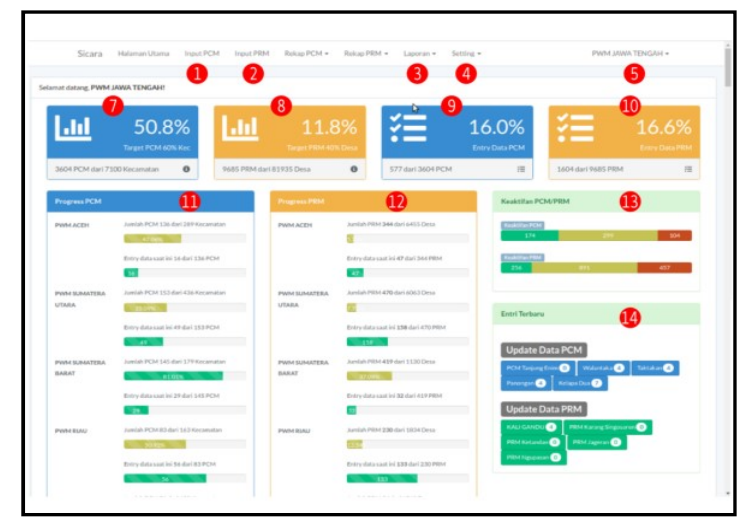

(a) Dashboard Sicara

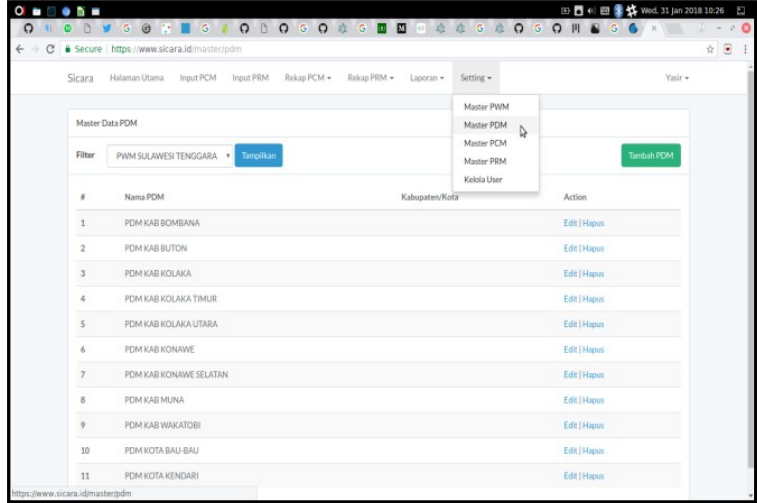

(b) List PDM

Gambar 5. Halaman Dashboard pada aplikasi sicara

\section{Setting Master PDM}

Pada menu setting (Gambar 6) pada urutan kedua adalah submenu untuk Master PDM yaitu untuk mengubah lokasi kabupaten/kota sebuah PDM. Ketika kita pilih submenu Master PDM maka akan ditampilkan list PDM yang ada di PWM yang kita pilih pada dropdown combo, seperti berikut :

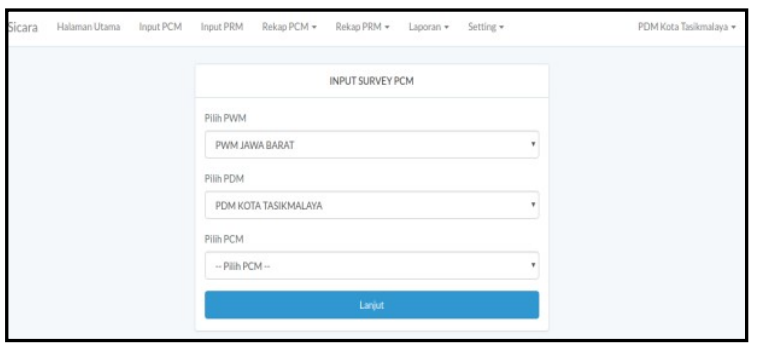

(a) Setting Master PDM

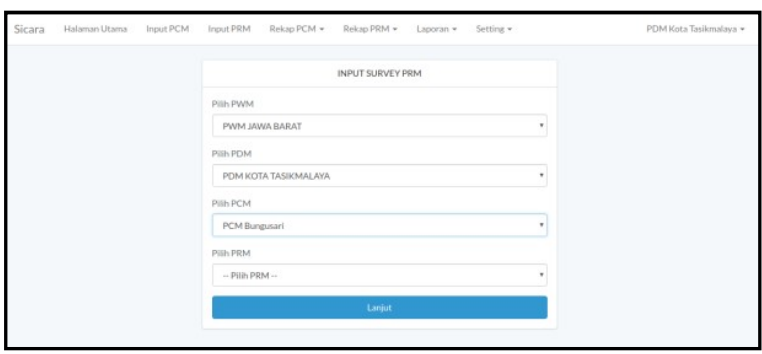

(b) Form Untuk Pilih PCM

Gambar 6. Input Data PCM

Input data PCM disini adalah untuk melakukan pendataan, menu ini tersedia pada dashboard. Klik pada menu input PCM maka akan tampil form untuk memilih PCM yang akan diinput datanya.. Pada form tersebut pengguna dapat memilih PCM yang akan diinput datanya dengan mengakses dropdown combo Pilih PCM. Kemudian tekan tombol Lanjut untuk masuk pada kuesioner. Pada kuesioner tersebut pengguna dapat mengisikan 
data sesuai dengan formulir yang telah diisi oleh PCM. Untuk ketentuan pengisian seperti tahun musycab di isi dengan angka tahunnya misal : 2014. Untuk pengisian jumlah mubaligh juga hanya diisi angka, misal jika jumlah mubaligh 20 orang, cukup ditulis angka 20

\section{Input Data PRM}

Input data PRM disini adalah untuk melakukan pendataan, menu ini tersedia pada dashboard. Klik pada menu input PRM maka akan tampil form untuk memilih PRM yang akan diinput datanya. Pada form tersebut pengguna dapat memilih PRM yang akan diinput datanya dengan mengakses dropdown combo Pilih PRM. Kemudian tekan tombol Lanjut untuk masuk pada kuesioner. Pada kuesioner tersebut pengguna dapat mengisikan data sesuai dengan formulir yang telah diisi oleh PRM. Untuk ketentuan pengisian seperti tahun musyran diisi dengan angka tahunnya misal : 2014. Untuk pengisian jumlah warga pilih perkiraan jumlahnya, misal 150 orang berarti pilih kurang dari 500 (sementara pengisian baru parameter perkiraan).

$\begin{array}{ll}\text { V. KESIMPULAN } \\ \text { Keberhasilan } & \text { sebuah program akan }\end{array}$
mempengaruhi pelaksanaan program yang lain. Di masa-masa awal organisasi, tantangan yang dihadapi bersifat materi dimana sumber daya material sangat terbatas, namun di sisi lain ada semangat dan solidaritas yang berlimpah. Tantangan generasi awal muhammadiyah adalah bagaimana membangun basis materi sehingga organisasi dapat berjalan dengan stabil. Namun di tahap lanjut perkembangan sebuah organisasi situasi menjadi terbalik, di mana ketika basis materi sudah mapan biasanya tantangan yang muncul adalah bagaimana membangun dan mempertahankan solidaritas agar organisasi tetap berjalan dengan kompak.

Untuk itu, pimpinan cabang dan ranting perlu menyadari tahapan perkembangan tersebut agar dapat mengantisipasi dengan lebih baik. Demikian laporan kegiatan ini kami sampaikan, atas perhatianya kami ucapkan terima kasih, semoga Allah SWT meridhoi atas segala usaha dan upaya yang kita lakukan, Amin.

\section{DAFTAR PUSTAKA}

[1] Tim LPCR PP Muhammadiyah 2015, Modul Pelatihan Pengambangan Cabang \&Ranting Muhammadiyah di terbitkan oleh LPCR PP Muhammadiyah

[2] Tim LPCR PP Muhammadiyah 2012 Panduan Penyelenggarana Pengajian Ranting Muhammadiyah di terbitkan oleh LPCR PP Muhammadiyah

[3] Tim LPCR PP Muhammadiyah 2012, Cabang dan Ranting Muhammadiyah Pilihan di terbitkan oleh LPCR PP Muhammadiyah

[4] Tim LPCR PP Muhammadiyah 2012, Peta Kondisi Cabang \& Ranting Muhammadiyah di terbitkan oleh LPCR PP Muhammadiyah

[5] Tim LPCR PP Muhammadiyah 2013, Pengembangan Ekonomi Anggota Ranting Muhammadiyah di terbitkan oleh LPCR PP Muhammadiyah

[6] Tim LPCR PP Muhammadiyah 2013, Gerakan Jama'ah dan dakwa Jama'ah (GJDJ) Di Ranting Muhammadiyah diterbitkan LPCR PP Muhammadiyah. 